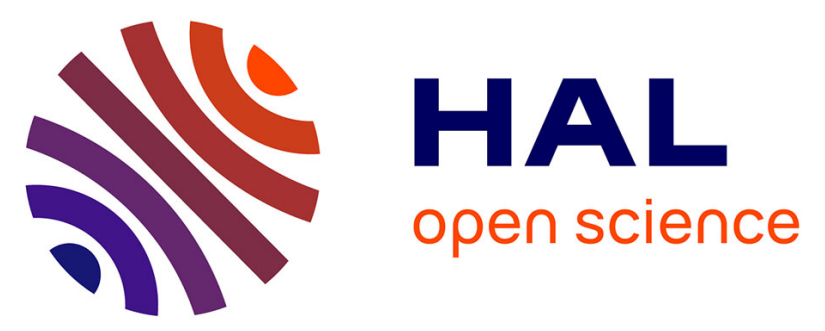

\title{
Protonation of Tetrapropoxy-4-tert-butylcalix[4]arene: NMR Study of Interaction and Probable Structures of the Product
}

\author{
Jaroslav Kriz, Jiri Dybal, Emanuel Makrlik, Jan Budka, Petr Vanura
}

\section{To cite this version:}

Jaroslav Kriz, Jiri Dybal, Emanuel Makrlik, Jan Budka, Petr Vanura. Protonation of Tetrapropoxy4-tert-butylcalix[4]arene: NMR Study of Interaction and Probable Structures of the Product. Supramolecular Chemistry, 2008, 20 (05), pp.487-494. 10.1080/10610270701422065 . hal-00513513

\section{HAL Id: hal-00513513 \\ https://hal.science/hal-00513513}

Submitted on 1 Sep 2010

HAL is a multi-disciplinary open access archive for the deposit and dissemination of scientific research documents, whether they are published or not. The documents may come from teaching and research institutions in France or abroad, or from public or private research centers.
L'archive ouverte pluridisciplinaire $\mathbf{H A L}$, est destinée au dépôt et à la diffusion de documents scientifiques de niveau recherche, publiés ou non, émanant des établissements d'enseignement et de recherche français ou étrangers, des laboratoires publics ou privés. 


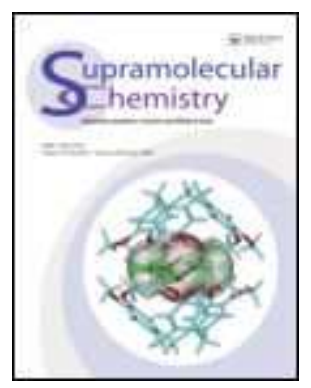

\section{Protonation of Tetrapropoxy-4-tert-butylcalix[4]arene: NMR Study of Interaction and Probable Structures of the Product}

\begin{tabular}{|r|l|}
\hline Journal: & Supramolecular Chemistry \\
\hline Manuscript ID: & GSCH-2007-0055.R1 \\
\hline Manuscript Type: & Full Paper \\
\hline Author: & 19-Apr-2007 \\
\hline Complete List of Authors: & $\begin{array}{l}\text { Kriz, Jaroslav; Institute of Macromolecular Chemistry, Structure } \\
\text { Analysis } \\
\text { Dybal, Jiri; Institute of Macromolecular Chemistry, Structure } \\
\text { Analysis } \\
\text { Makrlik, Emanuel; University of West Bohemia } \\
\text { Budka, Jan; Prague Institute of Chemical Technology } \\
\text { Vanura, Petr; Prague Institute of Chemical Technology }\end{array}$ \\
\hline Keywords: & Calixarene complex, calixarene protonation, NMR, DFT \\
\hline
\end{tabular}

\section{S ScholaronE \\ Manuscript Central}




\title{
Protonation of Tetrapropoxy-4-tert-butylcalix[4]arene: NMR Study of Interaction and Probable Structures of the Product
}

\author{
JAROSLAV KŘÍŽ ${ }^{a}$, JIŘÍ DYBAL $^{a}$, EMANUEL MAKRLÍK ${ }^{b}$, JAN BUDKA $^{c}$ and PETR \\ VAŇURA $^{c}$ \\ ${ }^{a}$ Institute of Macromolecular Chemistry, Academy of Sciences of the Czech Republic, \\ Heyrovského sq. 2, 16206 Prague, Czech Republic.E-mail: kriz@imc.cas.cz \\ ${ }^{b}$ Faculty of Applied Sciences, University of West Bohemia, Husova 11, 30614 Pilsen, Czech \\ Republic. \\ ${ }^{c}$ Prague Institute of Chemical Technology, Technická 5, 16628 Prague, Czech Republic.
}

Using ${ }^{1} \mathrm{H}$ and ${ }^{13} \mathrm{C}$ NMR spectroscopy, the interaction of tetrapropoxy-p-tert-butylcalix[4]arene (1) with $\mathrm{H}_{3} \mathrm{O}^{+}$ions produced by hydrogen bis(1,2-dicarbollyl) cobaltate (HDCC) and traces of water was studied in nitrobenzene- $d_{5}$. It was shown that 1 readily forms an equimolecular complex with $\mathrm{H}_{3} \mathrm{O}^{+}$. The equilibrium constant $K$ of its formation is 2.6 at $296 \mathrm{~K}$. Exchange between bound and free 1 is fast even under mild excess of HDCC, the correlation time $\tau_{\text {ex }}$ being about $0.13 \mathrm{~ms}$. NMR shows that $\mathrm{H}_{3} \mathrm{O}^{+}$is bound to the aryl-oxygen atoms and this binding forces the calixarene cup to adopt a more open and symmetrical conformation. This conclusion is in a full accord with high precision quantum DFT calculations which find one structure of the complex corresponding to a global energy minimum, in which the $\mathrm{H}_{3} \mathrm{O}^{+}$ion is bound to three of the oxygen atoms by strong hydrogen bonds and to the remaining oxygen by two weaker hydrogen bonds. The calixarene part is forced into a $\mathbf{C}_{4}$ symmetrical opened form.

When stored for weeks, the complex gradually transforms into other forms, most probably its hydrates, according to spectral evidence and DFT calculations.

Keywords: calixarene complex; calixarene protonation; NMR; DFT 


\section{INTRODUCTION}

Calixarene-based molecules have received intense attention in the recent years $[1,2]$. Many studies have focused on the binding ability of calixarene derivatives with carbonyl or analogous groups at their lower rims toward metal ions [3-12]. In our recent studies [13-15], we have shown that calixarenes carrying coordinating groups, such as dimethylthioamide, ester or keto groups on their lower rim, bind a hydroxonium ion $\mathrm{H}_{3} \mathrm{O}^{+}$in equimolecular and very stable complexes. NMR spectra and high-level quantum calculations revealed that $\mathrm{H}_{3} \mathrm{O}^{+}$ binds partly to the attached coordinating groups but also to the calixarene aryl-oxygen atoms. Quantum calculations even indicated that binding almost exclusively to the Ar-O- atoms could be even preferred in some cases. It is thus interesting to examine $\mathrm{H}_{3} \mathrm{O}^{+}$binding to a calixarene containing only Ar-O-R groups where $\mathrm{R}$ is an alkyl such as $n$-propyl in our case.

Like in our previous studies [13-15, 17, 18], hydrogen bis(1,2-dicarbollyl) cobaltate (HDCC)[16] was used as a reliable source of protons, which were converted to hydroxonium ions $\mathrm{H}_{3} \mathrm{O}^{+}$by a $3.1 \mathrm{~mol} / \mathrm{mol}$ excess of water. Combining NMR spectral evidence with DFT quantum mechanical calculations, we suggest the most probable structure of the protonated calixarene.

\section{RESULTS AND DISCUSSION}

NMR measurements. Our experiments with 1 (see Scheme 1) were carried out in nitrobenzene- $d_{5}$ as one of the sufficiently polar solvents (needed for full ionization of HDCC), which do not form inclusion complexes with calixarenes. After mixing 1 with increasing amounts of HDCC, its ${ }^{1} \mathrm{H}$ NMR signals gradually shift to a various degree as illustrated in Figure 1. The signal assignment corresponds to Scheme 1, where the protons are numbered in the same way as the carbons they are attached to. The signal shifts are analogous to those 
observed with other calixarene derivatives [13-15] as a sign of conformation change due to binding of $\mathrm{H}_{3} \mathrm{O}^{+}$ion at the lower rim.

As the signals shift immediately and without splitting, the protonation of $\mathbf{1}$ must be very fast. However, the persistent shift at larger excess of HDCC (cf. Figure 1) indicates that the product formation is not quantitative in the 1:1 mixture. We are thus dealing with a dynamic equilibrium, which is only moderately favorable to the complex.

Figure 1: $300.13 \mathrm{MHz}$ NMR spectra of calixarene 1 (A) and its 1:2 (B) and 1:4 mol/mol (C) mixtures with HDCC (nitrobenzene- $d_{5}, 296 \mathrm{~K}$ ). Signal assignment in A (cf. Scheme 1), extrapolated maximal shifts $\Delta \delta_{\max }$ (in ppm) in C, correlation times of exchange $\tau_{\mathrm{ex}}$ (in $\mathrm{ms}$ ) in $\mathrm{B}$.

\section{Scheme 1}

The equilibrium should follow the usual relation

$$
K=\frac{\left[\mathbf{1} \cdot \mathrm{H}^{+}\right]\left[\mathrm{A}^{-}\right]}{[\mathbf{1}]\left[\mathrm{A}^{-} \mathrm{H}^{+}\right]},
$$

where $\mathrm{A}^{-} \mathrm{H}^{+}$and $\mathrm{A}^{-}$stand for HDCC or any other suitable proton donor and its anion. Under fast exchange between free and coordinated 1, the actual chemical shift of any signal is a weighted average of the shifts corresponding to the exchanging sites. Thus the actual relative shift is $\Delta \delta=\alpha \Delta \delta_{\max }$, where $\alpha=\left[\mathbf{1} \cdot \mathrm{H}^{+}\right] /[1]_{0}$ and $\Delta \delta_{\max }$, obtained by extrapolation, is the maximum relative shift corresponding to the pure complex. Using Eq.1, $\Delta \delta$ can be expressed as

$$
\Delta \delta=\Delta \delta_{\max } \frac{K(1+\beta)-\sqrt{K^{2}(1+\beta)^{2}-4(K-1) K \beta}}{2(K-1)}
$$


where $\beta=\left[\mathrm{A}^{-} \mathrm{H}^{+}\right]_{0} /[1]_{0}$. Thus $K$ can be obtained by fitting Eq. 2 to the experimental values of $\Delta \delta$. Figure 2 shows $\Delta \delta$ of individual signals in the proton spectra of 1/HDCC mixtures and the fitting curves.

Figure 2: Relative shifts $\Delta \delta$ of signals in ${ }^{1} \mathrm{H}$ NMR spectrum of $\mathbf{1}$ and its mixtures with HDCC in nitrobenzene- $d_{5}$ at $296 \mathrm{~K}$ and their fitting with Equation 2.

The value of $K$ to which all the actual relative shifts fit is $2.61 \pm 0.03$. This is a much lower value than we observed in protonation of calixarenes bearing additional coordinating groups $[13-15]$

The apparent swiftness of exchange between free and bound $\mathbf{1}$ gives us the opportunity to examine its dynamics quantitatively. One of the possible methods is the measurement of transverse relaxation rate using the Carr-Purcell-Meiboom-Gill sequence (CPMG) [19] with a varied delay $t_{p}$ between the $\pi$ pulses. As shown by Luz and Meiboom [20], the actually measured relaxation rate $R_{2}\left(t_{p}\right)$ can be expressed as

$$
R_{2}\left(t_{p}\right)=R_{2}^{0}+p_{1} p_{2} \delta \omega^{2} \tau_{e x}\left[1-\left(\tau_{e x} / t_{p}\right) \tanh \left(t_{p} / \tau_{e x}\right)\right]
$$

where $R_{2}{ }^{0}$ is the part of relaxation rate independent of exchange, $p_{1}$ and $p_{2}$ are the probabilities of finding the nucleus at the sites 1 and 2 , respectively, $\delta \omega$ is the relative chemical shift between the two sites in rads and $\tau_{e x}$ is the correlation time of exchange. For short $\tau_{e x}$, Equation 3 can be approximated (slightly modifying the relations in Ref. 21) by

$$
R_{2}\left(t_{p}\right)=\zeta-\xi \tau_{e x}{ }^{2} / t_{p}
$$

with

$$
\zeta=R_{2}^{0}+\xi \tau_{e x}
$$

and

$$
\xi=4 \pi^{2} \alpha(1-\alpha)\left(\Delta \delta_{\max }\right)^{2}
$$


Figure 3: Dependence of the measured net increase in the transverse relaxation rate of the indicated most mobile signals in the $300.13 \mathrm{MHz}{ }^{1} \mathrm{H}$ NMR spectrum of the mixture of 1 with HDCC 1:2 (mol/mol) in nitrobenzene- $d_{5}$ at $296 \mathrm{~K}$

Returning now to the shape of ${ }^{1} \mathrm{H}$ NMR spectra, the $0.323 \mathrm{ppm}$ mutual approach of the signals $9 \mathrm{a}$ and $9 \mathrm{e}$ (axial and equatorial $\mathrm{CH}_{2}$ protons) relative to free $\mathbf{1}$ is a clear sign that the aromatic part of $\mathbf{1}$ adopts a more open and symmetric conformation in the complex [12]. This conclusion is corroborated by the significant deshielding of aromatic protons 4 , 8 . Such a change can be forced only by a $\mathrm{H}_{3} \mathrm{O}^{+}$binding at the lower rim of $\mathbf{1}$, i.e. to the aryl-oxygen atoms. In agreement with this, protons $10\left(\mathrm{O}_{-} \mathrm{CH}_{2}-\right)$ are significantly deshielded, too. Assuming that $\mathrm{H}_{3} \mathrm{O}^{+}$is bound by three strong hydrogen bonds [13-15], one would expect that one of the four $\mathrm{O}-\mathrm{CH}_{2}$ - groups should be perceptibly different from the other three. The shape of the proton (and also carbon, see below) spectrum indicates a $\mathrm{C}_{4}$ symmetry, however. There are two possible explanations of this behavior: either the $\mathrm{H}_{3} \mathrm{O}^{+}$ion adopts multiple weaker bonds to the fourth oxygen atom and is thus placed near to the center of the lower rim or it 
rotates very fast within the molecule averaging thus its structure in the NMR time window. Deciding between these two alternatives is beyond the abilities of NMR.

Most of the just described features can also be read out from the ${ }^{13} \mathrm{C}$ NMR spectra. Figure 4 reproduces DEPT45 spectra (showing only carbons with attached protons) of $\mathbf{1}$ and its $1: 4 \mathrm{~mol} / \mathrm{mol}$ mixture with HDCC, the latter having been measured 6 to 18 hours after mixing. Large downfield shifts of signals 4,8 and 10 leave no doubt that a complex was formed between $\mathbf{1}$ and $\mathrm{H}_{3} \mathrm{O}^{+}$, with the ion probably bound to the aryl-oxygen atoms. In analogy to proton spectra, the signals are single (except for small accompanying signals) suggesting thus again either $\mathrm{C}_{4}$ symmetry of the complex or fast averaging of the structure by internal motion.

Figure 4: $75.5 \mathrm{MHz}{ }^{13} \mathrm{C}$ NMR DEPT45 spectra of $5 \mathrm{mmol} / \mathrm{L}$ calixarene 1 (A) and its mixture with $4.0 \mathrm{~mol} / \mathrm{mol}$ excess of HDCC (B) $6-18 \mathrm{~h}$ after mixing (nitrobenzene- $d_{5}, 296$ $\mathrm{K})$. Assignment of signals in A (cf. Scheme 1), relative shifts (in ppm) in B.

However, measurement of long-range DEPT spectra designed to show signals of quaternary carbons shown in Figure 5 (which was more time-consuming and reflects thus a later stage of the development of the system) revealed splitting of carbon signals 5, 6 and 7 suggesting either lower symmetry of the complex or coexistence of two different structures. In addition to it, the smaller companions of each of the main signals, which already appeared in the normal DEPT45 spectra, somewhat increased in relative intensity. Evidently, a new variant of the complex is evolving very slowly from its original form and, as one can expect, the exchange between both forms is quite slow, too. Such multiple complex forms were already observed in the case of some calixarenes with attached ester and keto groups $[14,15]$ where the formation of the $\mathrm{H}_{3} \mathrm{O}^{+}$complex was very slow. In contrast to it, the formation of the present original complex is very fast although its equilibrium is less favorable. 
Figure 5: Parts of combined $75.5 \mathrm{MHz}{ }^{13} \mathrm{C}$ NMR DEPT45 and LR-DEPT45 spectra of 5 $\mathrm{mmol} / \mathrm{L}$ calixarene 1 (A) and its mixture with $4.0 \mathrm{~mol} / \mathrm{mol}$ excess of HDCC (B) 10 - 12 days after mixing (nitrobenzene- $d_{5}, 296 \mathrm{~K}$ )

Figure 6: Parts of $300.13 \mathrm{MHz}{ }^{1} \mathrm{H}$ NMR (above) and $75.5 \mathrm{MHz}{ }^{13} \mathrm{C}$ NMR DEPT45 (below) spectra of the mixture of $5 \mathrm{mmol} / \mathrm{L}$ calixarene 1 with $4.0 \mathrm{~mol} / \mathrm{mol}$ excess of HDCC measured 3 weeks after mixing (nitrobenzene- $d_{5}, 296 \mathrm{~K}$ ).

Inspection of the spectra of $\mathbf{1}$ - HDCC 1:4 mixture (see Figure 6, where the assignment of signals to individual forms was made using a combination of ${ }^{1} \mathrm{H}$ NOESY and ${ }^{1} \mathrm{H}_{-}{ }^{13} \mathrm{C}$ HSQC spectra) after 3 weeks of storage reveals two different new forms of the complex, B and C, produced from the original form A. The same new forms can be observed in a lower relative population in systems with a lower excess of HDCC, even in the 1:1 mixture. Therefore, it is not probable that the new forms are complexes with a higher number of $\mathrm{H}_{3} \mathrm{O}^{+}$ions. However, a 0.23 ppm downfield relative shift of the broad $\mathrm{H}_{2} \mathrm{O}$ signal (not shown) in the long-stored 1:4 mixture indicates that water takes part in the new forms. As it can be seen in Figure 6, the more prominent form $\mathrm{B}$ among the new products no longer exhibits $\mathrm{C}_{4}$ symmetry. Quite to the contrary, there is magnetic nonequivalence between at least two doubles of opposite aromatic rings (in the proton spectrum of $\mathrm{B}$, even all four tert-butyl groups are nonequivalent). Experience with NMR spectra of calixarenes teaches us that such nonequivalence should not be overvalued: due to their strong long-range shielding effects of the aromatic rings, even subtle changes in their relative orientation can lead to remarkable shifts of the signals of adjacent nuclei. Nevertheless, the observed nonequivalence cannot be ignored for two reasons: (i) it reflects lowering of the molecular symmetry from apparent $\mathrm{C}_{4}$ to $\mathrm{C}_{2}$ or even 
lower and (ii) it shows that the residence time in the exchange between nonequivalent analogous nuclei must be larger than $0.05 \mathrm{~s}$, i.e. the internal motion in the molecule $\mathrm{B}$ is at least two orders of magnitude slower than that in the form A. Therefore, the most plausible conclusion appears to be that the form B (and probably also C) is a hydrate of the complex A with a water molecule placed inside the calixarene cavity. The molecule has to sit near enough to the lower rim in order to interact with the bound $\mathrm{H}_{3} \mathrm{O}^{+}$ion, which necessarily means that it interacts with at least two opposite aromatic rings (probably by a weak hydrogen bond) lowering thus the symmetry of the complex and slowing down its internal motion.

Quantum chemical calculations. Geometry optimizations of calixarene and its complex with $\mathrm{H}_{3} \mathrm{O}^{+}$were performed by the quantum chemical calculations at the density functional level of theory (DFT, B3LYP functional) using the Gaussian 03 suite of programs [22]. The 6-31G(d) basis set was used and the optimization was unconstrained. The optimized structure of free calixarene is shown in Figure 7A. The most stable conformation forms a pinched cone structure with a $\mathrm{C}_{2}$ symmetry.

The structure obtained by optimization of the calixarene $-\mathrm{H}_{3} \mathrm{O}^{+}$complex is shown in Figure 7B, together with the lengths of hydrogen bonds (in $\AA$ ). Compared to free molecule the calixarene part of the complex is distorted so that its structure is very close to the $\mathrm{C}_{4}$ symmetry. The hydroxonium ion is placed in the cage formed by calixarene and is bound by strong hydrogen bonds to oxygen atoms of three C-O-C groups and by two somewhat weaker hydrogen bonds to the last C-O-C group. The stabilization energy of the complex calculated as the difference between the energies of the optimized complex and optimized free calixarene molecule and hydroxonium ion is $-394.72 \mathrm{~kJ} / \mathrm{mol}$. Stabilization energy of the complex can be expressed also with respect to the aqueous hydroxonium ion $\left[\mathrm{H}_{3} \mathrm{O}^{+}\left(\mathrm{H}_{2} \mathrm{O}\right)_{3}\right]$ and free calixarene (1) according to the formula

$$
\left[\mathrm{H}_{3} \mathrm{O}^{+}\left(\mathrm{H}_{2} \mathrm{O}\right)_{3}\right]+\mathbf{1} \rightarrow\left[\mathrm{H}_{3} \mathrm{O}^{+}(\mathbf{1})\right]+3 \mathrm{H}_{2} \mathrm{O}
$$


Then it is $-8.20 \mathrm{~kJ} / \mathrm{mol}$. This value, corrected further for entropy change, probably corresponds to the value of $K$ established above by NMR.

The gradual development of another form of the complex detected by NMR led us to explore its further possible changes or interactions. As the structure described above corresponds to the global energy minimum found by unconstrained geometry optimization, a new form could scarcely be produced by an internal rearrangement of the structure. We thus explored possible interactions of the complex with other components of the system. Nitrobenzene, which is largely prevalent in the system, does not appear do form any stable formation with the complex. However, water does. The calculated geometry of the complex hydrate is shown in Figure 8. The stabilization energy corresponding to such hydration is predicted to be $-19.75 \mathrm{~kJ} / \mathrm{mol}$, i.e. sufficiently high for the hydrate to be stable.

The interesting feature of the hydrate is that the water molecule is bound by the already bonded $\mathrm{H}_{3} \mathrm{O}^{+}$ion by a system of three medium-strong hydrogen bonds indicated in the Figure. In order to accomplish that, the water molecule has to penetrate the rather rigid and hydrophobic calixarene cavity (no other way apparently leads to a stable product), which can be expected to lead to rather long reaction times as observed. In addition, the water molecule also interacts with the aromatic systems by two weak hydrogen bonds (some of the

Figure 7: Optimized geometry of free $\mathbf{1}(\mathrm{A})$ and the $\mathbf{1} \cdot \mathrm{H}_{3} \mathrm{O}^{+}$complex (B) calculated at the B3LYP/6-31G(d) level (positions of hydrogen atoms in $\mathbf{1}$ are not shown)

$\mathrm{O}-\mathrm{H}-\mathrm{C}_{\mathrm{ar}}$ distances being as short as $2.55 \AA$ ). . In agreement with NMR spectra, these bonds without doubt slow down internal motions in the calixarene unit.

In contrast to NMR, however, we were not able to find any alternative stable form of the hydrate. Taking into account the fact that our calculations were done in vacuo (as no sufficiently reliable correction for the influence of polar medium has been found for this level 
of precision), we cannot be quite sure that other structural forms of the complex hydrate are excluded by theory.

Figure 8: Optimized geometry of the hydrated 1. $\mathrm{H}_{3} \mathrm{O}^{+}$complex calculated at the B3LYP/6-31G(d) level (positions of hydrogen atoms in $\mathbf{1}$ are not shown).

Conclusions. According to the evidence of ${ }^{1} \mathrm{H}$ and ${ }^{13} \mathrm{C}$ NMR spectra consistent with the predictions of high-precision DFT calculations, calixarene $\mathbf{1}$ binds the $\mathrm{H}_{3} \mathrm{O}^{+}$ion into an equimolecular complex. The formation of the main form of the complex, similarly as the exchange between free and bound $\mathbf{1}$, is very fast but the equilibrium is only moderately favorable to the complex. In the main form, $\mathrm{H}_{3} \mathrm{O}^{+}$is probably bound by three strong hydrogen bonds to three aryl-oxygen atoms of $\mathbf{1}$ and by two weaker hydrogen bonds to the remaining CO-C group. In contrast to free $\mathbf{1}$, the complex has almost $\mathrm{C}_{4}$ symmetry. Under prolonged storage of the complex-containing mixtures, small amounts of another form of the complex appear. It is evidently formed from the original complex and probably is the product of its hydration.

When compared with the calixarenes with strongly coordinating groups in addition to aryl-oxygen atoms at their lower rim [13-15], the present calixarene type clearly is a markedly less efficient complexing agent. From this one can conclude that the $\mathrm{C}-\mathrm{O}-\mathrm{C}$ groups, although they clearly participate in the complex $\mathrm{H}_{3} \mathrm{O}^{+}$binding in the former types [13-15], are as such less effective than in cooperation with e.g. dimethylamide, dimethylthioamide, ester and ketogroups.

\section{EXPERIMENTAL}

Materials and samples. Nitrobenzene- $d_{5}$ was purchased by Aldrich. Tetrapropoxy-p-tertbutylcalix[4]arene (1) was prepared by using the procedure published elsewhere [23]. 
Preparation of hydrogen bis(1,2-dicarbollyl) cobaltate (HDCC) was described earlier [16]. For NMR samples, $0.5 \times 10^{-5} \mathrm{~mol}$ of $\mathbf{1}$ was dissolved in a mixture of appropriate amounts of nitrobenzene- $d_{5}$ and $0.002 \mathrm{~mol} / \mathrm{L}$ solution of HDCC in the same solvent. The mixing and all subsequent measurements were done at $296 \mathrm{~K}$.

NMR spectra. ${ }^{1} \mathrm{H}$ and ${ }^{13} \mathrm{C}$ NMR spectra were measured in a quadrature detection mode at 300.13 and $75.45 \mathrm{MHz}$, respectively, with an upgraded Bruker Avance DPX300 spectrometer. 32 and 64 kpoints were measured for ${ }^{1} \mathrm{H}$ and ${ }^{13} \mathrm{C}$ NMR, respectively. ${ }^{1} \mathrm{H}$ NMR spectra were measured using a self-devised diffusion-filtering stimulated echo pulse sequence $-d_{1}-\pi / 2_{\varphi^{-}}$ GR- $\pi / 2_{\sigma}-d_{2}-\pi / 2_{-y}-G R-R E C_{x}$ in order to remove obscuring broad signals of water and nitrobenzene; $d_{1}$ and $d_{2}$ were $10 \mathrm{~s}$ and $60 \mathrm{~ms}$, respectively, the z-gradient GR was $50 \mathrm{G} / \mathrm{cm}$ and phase cycling was $\varphi=x, y,-x,-y, \sigma=\varphi+\pi / 2.128$ scans were collected for each spectrum. ${ }^{13} \mathrm{C}$ NMR measurements were performed using either the ${ }^{1} \mathrm{H}_{-}-{ }^{13} \mathrm{C}$ DEPT45 sequence (collecting 8000 scans) or its combination with its long-range variant optimized for the coupling constant $6 \mathrm{~Hz}$ (collecting at least 20000 scans); exponential weighting $(\mathrm{lb}=1 \mathrm{~Hz})$ was used before Fourier transform. In ${ }^{1} \mathrm{H}-{ }^{13} \mathrm{C} 2 \mathrm{D}$ HSQC and HMBC spectra used for signal assignment, 1028 points in F2 and 256 increments in F1 dimensions were measured using a zgradient inverse-detection probe.

Quantum mechanical calculations. Ab initio molecular orbital calculations were performed using the GAUSSIAN 03 suite of programs [16]. Molecular geometry was fully optimized at the B3LYP level of density functional theory (DFT) with the 6-31G(d) basis set. The optimization was unrestrained. Several local configurations near the achieved energy minimum were examined. As the renewed optimizations converged to the same molecular geometry, we believe the achieved energy minimum to be the global one. 
Acknowledgements. This work was supported by the Academy of Sciences of the Czech Republic, Project T400500402, and the Czech Ministry of Education, Youth and Sports, Projects MSM 4977751303 and MSM 6046137307.

\section{References}

1. Gutsche, C. D. Calixarenes Revisited. The Royal Society of Chemistry, Cambridge, 1998.

2. Böhmer, V. Angew. Chem., Int. Ed. Engl. 1995, 34, 713.

3. Arduini, A.; Pochini, A.; Reverberi, S.; Ungaro, R. Tetrahedron 1986, 42, 2089.

4. Arduini, A.; Ghidini, E.; Pochini, A.; Ungaro, R.; Andreetti, G.D.; Calestani, G.; Ugozzoli, F. J. Inclusion Phenom. 1988, 6, 119.

5. Arnaud-Neu, F.; Collins, E.M.; Deasy, M.; Ferguson, G.; Harris, S.J.; Kaitner, B.; Lough, A.J.; McKervey, M.A.; Marques, E.; Ruhl, B.L.; Schwing-Weill, M.J.; Seward, E.M. J. Am. Chem. Soc. 1989, 111, 8681.

6. Arnaud-Neu, F.; Barrett, G.; Harris, S.J.; Owens, M.; McKervey, M.A.; SchwingWeill, M.J.; Schwinté, P. Inorg. Chem. 1993, 32, 2644.

7. Ohto, K.; Murakami, E.; Shinohara, T.; Shiratsuchi, K.; Inoue, K.; Iwasaki, M. Anal. Chim. Acta 1997, 341, 275.

8. Ye, Z.; He, W.; Shi, X.; Zhu, L. J. Coord. Chem. 2001, 54, 105.

9. Danil de Namor, A.F.; Chahine, S.; Kowalska, D.; Castellano, E.E.; Piro, O.E. J. Am. Chem. Soc. 2002, 124, 12824.

10. Marcos, P. M.; Ascenso, J.R.; Segurado, M.A.P.; Pereira, J.L.C. J. Inclusion Phenom. 2002, 42, 281.

11. Marcos, P.M.; Félix, S.; Ascenso, J.R.; Segurado, M.A.P.; Pereira, J.L.C.; KhazaeliParsa, P.; Hubscher-Bruder, V.; Arnaud-Neu, F. New J.Chem. 2004, 28, 748.

12. Gutsche, C. D. Aldrichimica Acta 1995, $28,3$.

13. Křriž, J.; Dybal, J.; Makrlík, E.; Vaňura, P. Supramol. Chem. in print.

14. Křŕž, J.; Dybal, J.; Makrlík, E.; Vaňura, P. Supramol. Chem. in print.

15. Křŕž, J.; Dybal, J.; Makrlík, E.; Budka, J; Vaňura, P. Monatsh. Chem. in print.

16. Makrlík, E.; Vaňura, P. Talanta 1985, 32, 423.

17. Kříž, J.; Makrlík, E.; Vaňura, P. Biopolymers 2006, 81, 104.

18. Kř́íž, J.; Dybal, J.; Makrlík, E. Biopolymers 2006, 82, 536.

19. Meiboom, S.; Gill, D. Rev. Sci. Instrum. 1958, 29, 688.

20. Luz, L.; Meiboom, S. J. Chem. Phys. 1963, 39, 366. 
21. Canet, D.; Robert, J.B. in Dynamics of Solutions and Fluid Mixtures by NMR (J. J. Delpuech Ed.), Wiley, Chichester 1995, p. 127.

22. Frisch, M. J.; Trucks, G. W.; Schlegel, H. B.; Scuseria, G. E.; Robb, M. A.; Cheeseman, J. R.; Montgomery, Jr., J. A.; Vreven, T.; Kudin, K. N.; Burant, J. C.; Millam, J. M.; Iyengar, S. S.; Tomasi, J.; Barone, V.; Mennucci, B.; Cossi, M.; Scalmani, G.; Rega, N.; Petersson, G. A.; Nakatsuji, H.; Hada, M.; Ehara, M.; Toyota, K.; Fukuda, R.; Hasegawa, J.; Ishida, M.; Nakajima, T.; Honda, Y.; Kitao, O.; Nakai, H.; Klene, M.; Li, X.; Knox, J. E.; Hratchian, H. P.; Cross, J. B.; Bakken, V.; Adamo, C.; Jaramillo, J.; Gomperts, R.; Stratmann, R. E.; Yazyev, O.; Austin, A. J.; Cammi, R.; Pomelli, C.; Ochterski, J. W.; Ayala, P. Y.; Morokuma, K.; Voth, G. A.; Salvador, P.; Dannenberg, J. J.; Zakrzewski, V. G.; Dapprich, S.; Daniels, A. D.; Strain, M. C.; Farkas, O.; Malick, D. K.; Rabuck, A. D.; Raghavachari, K.; Foresman, J. B.; Ortiz, J. V.; Cui, Q.; Baboul, A. G.; Clifford, S.; Cioslowski, J.; Stefanov, B. B.; Liu, G.; Liashenko, A.; Piskorz, P.; Komaromi, I.; Martin, R. L.; Fox, D. J.; Keith, T.; AlLaham, M. A.; Peng, C. Y.; Nanayakkara, A.; Challacombe, M.; Gill, P. M. W.; Johnson, B.; Chen, W.; Wong, M. W.; Gonzalez, C.; and Pople, J. A. Gaussian 03, Revision C.02; Gaussian, Inc.: Wallingford CT, 2004.

23. Kelderman, E.; Derhaeg, L.; Heesink, G.J.T.; Verboom, W.; Engbersen, J.F.J.; van Hulst, N.F.; Persoons, A.; Reinhoudt, D.N. Angew. Chem. 1992, 104, 1107. 


\title{
Protonation of Tetrapropoxy-4-tert-butylcalix[4]arene: NMR Study of Interaction and Probable Structures of the Product
}

\author{
JAROSLAV KŘÍŽ ${ }^{a}$, JIŘÍ DYBAL $^{a}$, EMANUEL MAKRLÍK ${ }^{b}$, JAN BUDKA $^{c}$ and PETR \\ VAŇURA $^{c}$ \\ ${ }^{a}$ Institute of Macromolecular Chemistry, Academy of Sciences of the Czech Republic, \\ Heyrovského sq. 2, 16206 Prague, Czech Republic.E-mail: kriz@imc.cas.cz \\ ${ }^{b}$ Faculty of Applied Sciences, University of West Bohemia, Husova 11, 30614 Pilsen, Czech \\ Republic. \\ ${ }^{c}$ Prague Institute of Chemical Technology, Technická 5, 16628 Prague, Czech Republic.
}

Using ${ }^{1} \mathrm{H}$ and ${ }^{13} \mathrm{C}$ NMR spectroscopy, the interaction of tetrapropoxy-p-tert-butylcalix[4]arene (1) with $\mathrm{H}_{3} \mathrm{O}^{+}$ions produced by hydrogen bis(1,2-dicarbollyl) cobaltate (HDCC) and traces of water was studied in nitrobenzene- $d_{5}$. It was shown that 1 readily forms an equimolecular complex with $\mathrm{H}_{3} \mathrm{O}^{+}$. The equilibrium constant $K$ of its formation is 2.6 at $296 \mathrm{~K}$. Exchange between bound and free 1 is fast even under mild excess of HDCC, the correlation time $\tau_{\text {ex }}$ being about $0.13 \mathrm{~ms}$. NMR shows that $\mathrm{H}_{3} \mathrm{O}^{+}$is bound to the aryl-oxygen atoms and this binding forces the calixarene cup to adopt a more open and symmetrical conformation. This conclusion is in a full accord with high precision quantum DFT calculations which find one structure of the complex corresponding to a global energy minimum, in which the $\mathrm{H}_{3} \mathrm{O}^{+}$ion is bound to three of the oxygen atoms by strong hydrogen bonds and to the remaining oxygen by two weaker hydrogen bonds. The calixarene part is forced into a $\mathrm{C}_{4}$ symmetrical opened form.

When stored for weeks, the complex gradually transforms into other forms, most probably its hydrates, according to spectral evidence and DFT calculations.

Keywords: calixarene complex; calixarene protonation; NMR; DFT 


\section{INTRODUCTION}

Calixarene-based molecules have received intense attention in the recent years $[1,2]$. Many studies have focused on the binding ability of calixarene derivatives with carbonyl or analogous groups at their lower rims toward metal ions [3-12]. In our recent studies [13-15], we have shown that calixarenes carrying coordinating groups, such as dimethylthioamide, ester or keto groups on their lower rim, bind a hydroxonium ion $\mathrm{H}_{3} \mathrm{O}^{+}$in equimolecular and very stable complexes. NMR spectra and high-level quantum calculations revealed that $\mathrm{H}_{3} \mathrm{O}^{+}$ binds partly to the attached coordinating groups but also to the calixarene aryl-oxygen atoms. Quantum calculations even indicated that binding almost exclusively to the Ar-O- atoms could be even preferred in some cases. It is thus interesting to examine $\mathrm{H}_{3} \mathrm{O}^{+}$binding to a calixarene containing only Ar-O-R groups where $\mathrm{R}$ is an alkyl such as $n$-propyl in our case.

Like in our previous studies [13-15, 17, 18], hydrogen bis(1,2-dicarbollyl) cobaltate (HDCC)[16] was used as a reliable source of protons, which were converted to hydroxonium ions $\mathrm{H}_{3} \mathrm{O}^{+}$by a $3.1 \mathrm{~mol} / \mathrm{mol}$ excess of water. Combining NMR spectral evidence with DFT quantum mechanical calculations, we suggest the most probable structure of the protonated calixarene.

\section{RESULTS AND DISCUSSION}

NMR measurements. Our experiments with 1 (see Scheme 1) were carried out in nitrobenzene- $d_{5}$ as one of the sufficiently polar solvents (needed for full ionization of HDCC), which do not form inclusion complexes with calixarenes. After mixing $\mathbf{1}$ with increasing amounts of HDCC, its ${ }^{1} \mathrm{H}$ NMR signals gradually shift to a various degree as illustrated in Figure 1. The signal assignment corresponds to Scheme 1, where the protons are numbered in the same way as the carbons they are attached to. The signal shifts are analogous to those 
observed with other calixarene derivatives [13-15] as a sign of conformation change due to binding of $\mathrm{H}_{3} \mathrm{O}^{+}$ion at the lower rim.

As the signals shift immediately and without splitting, the protonation of 1 must be very fast. However, the persistent shift at larger excess of HDCC (cf. Figure 1) indicates that the product formation is not quantitative in the 1:1 mixture. We are thus dealing with a dynamic equilibrium, which is only moderately favorable to the complex.

Figure 1: $300.13 \mathrm{MHz}$ NMR spectra of calixarene 1 (A) and its 1:2 (B) and 1:4 mol/mol (C) mixtures with HDCC (nitrobenzene- $d_{5}, 296 \mathrm{~K}$ ). Signal assignment in A (cf. Scheme 1), extrapolated maximal shifts $\Delta \delta_{\max }$ (in ppm) in C, correlation times of exchange $\tau_{\text {ex }}$ (in $\mathrm{ms}$ ) in $\mathrm{B}$.

\section{Scheme 1}

The equilibrium should follow the usual relation

$$
K=\frac{\left[1 \cdot \mathrm{H}^{+}\right]\left[\mathrm{A}^{-}\right]}{[1]\left[\mathrm{A}^{-} \mathrm{H}^{+}\right]},
$$

where $\mathrm{A}^{-} \mathrm{H}^{+}$and $\mathrm{A}^{-}$stand for HDCC or any other suitable proton donor and its anion. Under fast exchange between free and coordinated 1, the actual chemical shift of any signal is a weighted average of the shifts corresponding to the exchanging sites. Thus the actual relative shift is $\Delta \delta=\alpha \Delta \delta_{\max }$, where $\alpha=\left[\mathbf{1} \cdot \mathrm{H}^{+}\right] /[1]_{0}$ and $\Delta \delta_{\max }$, obtained by extrapolation, is the maximum relative shift corresponding to the pure complex. Using Eq.1, $\Delta \delta$ can be expressed as

$$
\Delta \delta=\Delta \delta_{\max } \frac{K(1+\beta)-\sqrt{K^{2}(1+\beta)^{2}-4(K-1) K \beta}}{2(K-1)},
$$


where $\beta=\left[\mathrm{A}^{-} \mathrm{H}^{+}\right]_{0} /[1]_{0}$. Thus $K$ can be obtained by fitting Eq. 2 to the experimental values of $\Delta \delta$. Figure 2 shows $\Delta \delta$ of individual signals in the proton spectra of $1 /$ HDCC mixtures and the fitting curves.

Figure 2: Relative shifts $\Delta \delta$ of signals in ${ }^{1} \mathrm{H}$ NMR spectrum of $\mathbf{1}$ and its mixtures with HDCC in nitrobenzene- $d_{5}$ at $296 \mathrm{~K}$ and their fitting with Equation 2.

The value of $K$ to which all the actual relative shifts fit is $2.61 \pm 0.03$. This is a much lower value than we observed in protonation of calixarenes bearing additional coordinating groups $[13-15]$

The apparent swiftness of exchange between free and bound $\mathbf{1}$ gives us the opportunity to examine its dynamics quantitatively. One of the possible methods is the measurement of transverse relaxation rate using the Carr-Purcell-Meiboom-Gill sequence (CPMG) [19] with a varied delay $t_{p}$ between the $\pi$ pulses. As shown by Luz and Meiboom [20], the actually measured relaxation rate $R_{2}\left(t_{p}\right)$ can be expressed as

$$
R_{2}\left(t_{p}\right)=R_{2}^{0}+p_{1} p_{2} \delta \omega^{2} \tau_{e x}\left[1-\left(\tau_{e x} / t_{p}\right) \tanh \left(t_{p} / \tau_{e x}\right)\right]
$$

where $R_{2}{ }^{0}$ is the part of relaxation rate independent of exchange, $p_{1}$ and $p_{2}$ are the probabilities of finding the nucleus at the sites 1 and 2 , respectively, $\delta \omega$ is the relative chemical shift between the two sites in rads and $\tau_{e x}$ is the correlation time of exchange. For short $\tau_{e x}$, Equation 3 can be approximated (slightly modifying the relations in Ref. 21) by

$$
R_{2}\left(t_{p}\right)=\zeta-\xi \tau_{e x}{ }^{2} / t_{p}
$$

with

$$
\zeta=R_{2}^{0}+\xi \tau_{e x}
$$

and

$$
\xi=4 \pi^{2} \alpha(1-\alpha)\left(\Delta \delta_{\max }\right)^{2}
$$


where $\Delta \delta_{\max }$ is the relative shift (in $\mathrm{Hz}$ ) of the given signal between free $\mathbf{1}$ and its complex. Thus the dependence of $R_{2}\left(t_{p}\right)$ on $1 / t_{p}$ is linear with the slope $\xi_{e x}{ }_{e x}^{2}$. As $\Delta \delta_{\max }$ is obtained by extrapolation from the spectra and $\alpha$ can be calculated from actual $\Delta \delta$ (see above), obtaining $\tau_{e x}$ from the slope is straightforward. Figure 3 shows dependences for three most mobile signals in the proton spectrum of the $\mathbf{1} / \mathrm{HDCC}$ mixture $1: 2 \mathrm{~mol} / \mathrm{mol}$, namely $4+8,10$ and $9 \mathrm{e}$. The values of $\tau_{e x}$ obtained from the individual slopes are $1.33 \times 10^{-4}, 1.36 \times 10^{-4}$, and $1.24 \times 10^{-4} \mathrm{~s}$, respectively. These values are sufficiently close to each other to have a physical meaning of the correlation time of exchange between free and bound forms of 1. Evidently, the exchange is quite fast, its rate constant being about $7.6 \times 10^{3} \mathrm{~s}^{-1}$.

Figure 3: Dependence of the measured net increase in the transverse relaxation rate of the indicated most mobile signals in the $300.13 \mathrm{MHz}{ }^{1} \mathrm{H}$ NMR spectrum of the mixture of 1 with HDCC 1:2 (mol/mol) in nitrobenzene- $d_{5}$ at $296 \mathrm{~K}$

Returning now to the shape of ${ }^{1} \mathrm{H}$ NMR spectra, the $0.323 \mathrm{ppm}$ mutual approach of the signals $9 \mathrm{a}$ and $9 \mathrm{e}$ (axial and equatorial $\mathrm{CH}_{2}$ protons) relative to free $\mathbf{1}$ is a clear sign that the aromatic part of $\mathbf{1}$ adopts a more open and symmetric conformation in the complex [12]. This conclusion is corroborated by the significant deshielding of aromatic protons 4 , 8 . Such a change can be forced only by a $\mathrm{H}_{3} \mathrm{O}^{+}$binding at the lower rim of 1 , i.e. to the aryl-oxygen atoms. In agreement with this, protons $10\left(\mathrm{O}_{-} \mathrm{CH}_{2}-\right)$ are significantly deshielded, too. Assuming that $\mathrm{H}_{3} \mathrm{O}^{+}$is bound by three strong hydrogen bonds [13-15], one would expect that one of the four $\mathrm{O}-\mathrm{CH}_{2}$ - groups should be perceptibly different from the other three. The shape of the proton (and also carbon, see below) spectrum indicates a $\mathrm{C}_{4}$ symmetry, however. There are two possible explanations of this behavior: either the $\mathrm{H}_{3} \mathrm{O}^{+}$ion adopts multiple weaker bonds to the fourth oxygen atom and is thus placed near to the center of the lower rim or it 
rotates very fast within the molecule averaging thus its structure in the NMR time window. Deciding between these two alternatives is beyond the abilities of NMR.

Most of the just described features can also be read out from the ${ }^{13} \mathrm{C}$ NMR spectra. Figure 4 reproduces DEPT45 spectra (showing only carbons with attached protons) of 1 and its $1: 4 \mathrm{~mol} / \mathrm{mol}$ mixture with HDCC, the latter having been measured 6 to 18 hours after mixing. Large downfield shifts of signals 4,8 and 10 leave no doubt that a complex was formed between $\mathbf{1}$ and $\mathrm{H}_{3} \mathrm{O}^{+}$, with the ion probably bound to the aryl-oxygen atoms. In analogy to proton spectra, the signals are single (except for small accompanying signals) suggesting thus again either $\mathrm{C}_{4}$ symmetry of the complex or fast averaging of the structure by internal motion.

Figure 4: $75.5 \mathrm{MHz}{ }^{13} \mathrm{C}$ NMR DEPT45 spectra of $5 \mathrm{mmol} / \mathrm{L}$ calixarene 1 (A) and its mixture with $4.0 \mathrm{~mol} / \mathrm{mol}$ excess of HDCC (B) $6-18 \mathrm{~h}$ after mixing (nitrobenzene- $d_{5}, 296$ $\mathrm{K}$ ). Assignment of signals in A (cf. Scheme 1), relative shifts (in ppm) in B.

However, measurement of long-range DEPT spectra designed to show signals of quaternary carbons shown in Figure 5 (which was more time-consuming and reflects thus a later stage of the development of the system) revealed splitting of carbon signals 5, 6 and 7 suggesting either lower symmetry of the complex or coexistence of two different structures. In addition to it, the smaller companions of each of the main signals, which already appeared in the normal DEPT45 spectra, somewhat increased in relative intensity. Evidently, a new variant of the complex is evolving very slowly from its original form and, as one can expect, the exchange between both forms is quite slow, too. Such multiple complex forms were already observed in the case of some calixarenes with attached ester and keto groups $[14,15]$ where the formation of the $\mathrm{H}_{3} \mathrm{O}^{+}$complex was very slow. In contrast to it, the formation of the present original complex is very fast although its equilibrium is less favorable. 
Figure 5: Parts of combined $75.5 \mathrm{MHz}{ }^{13} \mathrm{C}$ NMR DEPT45 and LR-DEPT45 spectra of 5 $\mathrm{mmol} / \mathrm{L}$ calixarene 1 (A) and its mixture with $4.0 \mathrm{~mol} / \mathrm{mol}$ excess of HDCC (B) 10 - 12 days after mixing (nitrobenzene- $d_{5}, 296 \mathrm{~K}$ )

Figure 6: Parts of $300.13 \mathrm{MHz}{ }^{1} \mathrm{H}$ NMR (above) and $75.5 \mathrm{MHz}{ }^{13} \mathrm{C}$ NMR DEPT45 (below) spectra of the mixture of $5 \mathrm{mmol} / \mathrm{L}$ calixarene 1 with $4.0 \mathrm{~mol} / \mathrm{mol}$ excess of HDCC measured 3 weeks after mixing (nitrobenzene- $d_{5}, 296 \mathrm{~K}$ ).

Inspection of the spectra of 1 - HDCC 1:4 mixture (see Figure 6, where the assignment of signals to individual forms was made using a combination of ${ }^{1} \mathrm{H}$ NOESY and ${ }^{1} \mathrm{H}_{-}{ }^{13} \mathrm{C}$ HSQC spectra) after 3 weeks of storage reveals two different new forms of the complex, B and C, produced from the original form A. The same new forms can be observed in a lower relative population in systems with a lower excess of HDCC, even in the 1:1 mixture. Therefore, it is not probable that the new forms are complexes with a higher number of $\mathrm{H}_{3} \mathrm{O}^{+}$ions. However, a 0.23 ppm downfield relative shift of the broad $\mathrm{H}_{2} \mathrm{O}$ signal (not shown) in the long-stored 1:4 mixture indicates that water takes part in the new forms. As it can be seen in Figure 6, the more prominent form $\mathrm{B}$ among the new products no longer exhibits $\mathrm{C}_{4}$ symmetry. Quite to the contrary, there is magnetic nonequivalence between at least two doubles of opposite aromatic rings (in the proton spectrum of $\mathrm{B}$, even all four tert-butyl groups are nonequivalent). Experience with NMR spectra of calixarenes teaches us that such nonequivalence should not be overvalued: due to their strong long-range shielding effects of the aromatic rings, even subtle changes in their relative orientation can lead to remarkable shifts of the signals of adjacent nuclei. Nevertheless, the observed nonequivalence cannot be ignored for two reasons: (i) it reflects lowering of the molecular symmetry from apparent $C_{4}$ to $C_{2}$ or even 
lower and (ii) it shows that the residence time in the exchange between nonequivalent analogous nuclei must be larger than $0.05 \mathrm{~s}$, i.e. the internal motion in the molecule $\mathrm{B}$ is at least two orders of magnitude slower than that in the form A. Therefore, the most plausible conclusion appears to be that the form B (and probably also C) is a hydrate of the complex A with a water molecule placed inside the calixarene cavity. The molecule has to sit near enough to the lower rim in order to interact with the bound $\mathrm{H}_{3} \mathrm{O}^{+}$ion, which necessarily means that it interacts with at least two opposite aromatic rings (probably by a weak hydrogen bond) lowering thus the symmetry of the complex and slowing down its internal motion.

Quantum chemical calculations. Geometry optimizations of calixarene and its complex with $\mathrm{H}_{3} \mathrm{O}^{+}$were performed by the quantum chemical calculations at the density functional level of theory (DFT, B3LYP functional) using the Gaussian 03 suite of programs [22]. The 6-31G(d) basis set was used and the optimization was unconstrained. The optimized structure of free calixarene is shown in Figure 7A. The most stable conformation forms a pinched cone structure with a $\mathrm{C}_{2}$ symmetry.

The structure obtained by optimization of the calixarene $-\mathrm{H}_{3} \mathrm{O}^{+}$complex is shown in Figure 7B, together with the lengths of hydrogen bonds (in $\AA$ ). Compared to free molecule the calixarene part of the complex is distorted so that its structure is very close to the $\mathrm{C}_{4}$ symmetry. The hydroxonium ion is placed in the cage formed by calixarene and is bound by strong hydrogen bonds to oxygen atoms of three C-O-C groups and by two somewhat weaker hydrogen bonds to the last C-O-C group. The stabilization energy of the complex calculated as the difference between the energies of the optimized complex and optimized free calixarene molecule and hydroxonium ion is $-394.72 \mathrm{~kJ} / \mathrm{mol}$. Stabilization energy of the complex can be expressed also with respect to the aqueous hydroxonium ion $\left[\mathrm{H}_{3} \mathrm{O}^{+}\left(\mathrm{H}_{2} \mathrm{O}\right)_{3}\right]$ and free calixarene (1) according to the formula

$$
\left[\mathrm{H}_{3} \mathrm{O}^{+}\left(\mathrm{H}_{2} \mathrm{O}\right)_{3}\right]+\mathbf{1} \rightarrow\left[\mathrm{H}_{3} \mathrm{O}^{+}(\mathbf{1})\right]+3 \mathrm{H}_{2} \mathrm{O} \text {. }
$$


Then it is $-8.20 \mathrm{~kJ} / \mathrm{mol}$. This value, corrected further for entropy change, probably corresponds to the value of $K$ established above by NMR.

The gradual development of another form of the complex detected by NMR led us to explore its further possible changes or interactions. As the structure described above corresponds to the global energy minimum found by unconstrained geometry optimization, a new form could scarcely be produced by an internal rearrangement of the structure. We thus explored possible interactions of the complex with other components of the system. Nitrobenzene, which is largely prevalent in the system, does not appear do form any stable formation with the complex. However, water does. The calculated geometry of the complex hydrate is shown in Figure 8. The stabilization energy corresponding to such hydration is predicted to be $-19.75 \mathrm{~kJ} / \mathrm{mol}$, i.e. sufficiently high for the hydrate to be stable.

The interesting feature of the hydrate is that the water molecule is bound by the already bonded $\mathrm{H}_{3} \mathrm{O}^{+}$ion by a system of three medium-strong hydrogen bonds indicated in the Figure. In order to accomplish that, the water molecule has to penetrate the rather rigid and hydrophobic calixarene cavity (no other way apparently leads to a stable product), which can be expected to lead to rather long reaction times as observed. In addition, the water molecule also interacts with the aromatic systems by two weak hydrogen bonds (some of the

Figure 7: Optimized geometry of free $\mathbf{1}(\mathrm{A})$ and the $\mathbf{1} \cdot \mathrm{H}_{3} \mathrm{O}^{+}$complex (B) calculated at the B3LYP/6-31G(d) level (positions of hydrogen atoms in $\mathbf{1}$ are not shown)

O-H-C $\mathrm{C}_{\mathrm{ar}}$ distances being as short as $2.55 \AA$ Á). In agreement with NMR spectra, these bonds without doubt slow down internal motions in the calixarene unit.

In contrast to NMR, however, we were not able to find any alternative stable form of the hydrate. Taking into account the fact that our calculations were done in vacuo (as no sufficiently reliable correction for the influence of polar medium has been found for this level 
of precision), we cannot be quite sure that other structural forms of the complex hydrate are excluded by theory.

Figure 8: Optimized geometry of the hydrated 1. $\mathrm{H}_{3} \mathrm{O}^{+}$complex calculated at the B3LYP/6-31G(d) level (positions of hydrogen atoms in $\mathbf{1}$ are not shown).

Conclusions. According to the evidence of ${ }^{1} \mathrm{H}$ and ${ }^{13} \mathrm{C}$ NMR spectra consistent with the predictions of high-precision DFT calculations, calixarene $\mathbf{1}$ binds the $\mathrm{H}_{3} \mathrm{O}^{+}$ion into an equimolecular complex. The formation of the main form of the complex, similarly as the exchange between free and bound $\mathbf{1}$, is very fast but the equilibrium is only moderately favorable to the complex. In the main form, $\mathrm{H}_{3} \mathrm{O}^{+}$is probably bound by three strong hydrogen bonds to three aryl-oxygen atoms of $\mathbf{1}$ and by two weaker hydrogen bonds to the remaining $\mathrm{C}$ O-C group. In contrast to free $\mathbf{1}$, the complex has almost $\mathrm{C}_{4}$ symmetry. Under prolonged storage of the complex-containing mixtures, small amounts of another form of the complex appear. It is evidently formed from the original complex and probably is the product of its hydration.

When compared with the calixarenes with strongly coordinating groups in addition to aryl-oxygen atoms at their lower rim [13-15], the present calixarene type clearly is a markedly less efficient complexing agent. From this one can conclude that the C-O-C groups, although they clearly participate in the complex $\mathrm{H}_{3} \mathrm{O}^{+}$binding in the former types [13-15], are as such less effective than in cooperation with e.g. dimethylamide, dimethylthioamide, ester and ketogroups.

\section{EXPERIMENTAL}

Materials and samples. Nitrobenzene- $d_{5}$ was purchased by Aldrich. Tetrapropoxy-p-tertbutylcalix[4]arene (1) was prepared by using the procedure published elsewhere [23]. 
Preparation of hydrogen bis(1,2-dicarbollyl) cobaltate (HDCC) was described earlier [16]. For NMR samples, $0.5 \times 10^{-5} \mathrm{~mol}$ of $\mathbf{1}$ was dissolved in a mixture of appropriate amounts of nitrobenzene- $d_{5}$ and $0.002 \mathrm{~mol} / \mathrm{L}$ solution of HDCC in the same solvent. The mixing and all subsequent measurements were done at $296 \mathrm{~K}$.

NMR spectra. ${ }^{1} \mathrm{H}$ and ${ }^{13} \mathrm{C}$ NMR spectra were measured in a quadrature detection mode at 300.13 and $75.45 \mathrm{MHz}$, respectively, with an upgraded Bruker Avance DPX300 spectrometer. 32 and 64 kpoints were measured for ${ }^{1} \mathrm{H}$ and ${ }^{13} \mathrm{C}$ NMR, respectively. ${ }^{1} \mathrm{H}$ NMR spectra were measured using a self-devised diffusion-filtering stimulated echo pulse sequence $-d_{1}-\pi / 2_{\varphi^{-}}$ GR- $\pi / 2_{\sigma}-d_{2}-\pi / 2_{-y}-G R-R E C_{x}$ in order to remove obscuring broad signals of water and nitrobenzene; $d_{1}$ and $d_{2}$ were $10 \mathrm{~s}$ and $60 \mathrm{~ms}$, respectively, the z-gradient GR was $50 \mathrm{G} / \mathrm{cm}$ and phase cycling was $\varphi=x, y,-x,-y, \sigma=\varphi+\pi / 2.128$ scans were collected for each spectrum. ${ }^{13} \mathrm{C}$ NMR measurements were performed using either the ${ }^{1} \mathrm{H}-{ }^{13} \mathrm{C}$ DEPT45 sequence (collecting 8000 scans) or its combination with its long-range variant optimized for the coupling constant $6 \mathrm{~Hz}$ (collecting at least 20000 scans); exponential weighting $(\mathrm{lb}=1 \mathrm{~Hz})$ was used before Fourier transform. In ${ }^{1} \mathrm{H}-{ }^{13} \mathrm{C} 2 \mathrm{D}$ HSQC and HMBC spectra used for signal assignment, 1028 points in F2 and 256 increments in F1 dimensions were measured using a zgradient inverse-detection probe.

Quantum mechanical calculations. Ab initio molecular orbital calculations were performed using the GAUSSIAN 03 suite of programs [16]. Molecular geometry was fully optimized at the B3LYP level of density functional theory (DFT) with the 6-31G(d) basis set. The optimization was unrestrained. Several local configurations near the achieved energy minimum were examined. As the renewed optimizations converged to the same molecular geometry, we believe the achieved energy minimum to be the global one. 
Acknowledgements. This work was supported by the Academy of Sciences of the Czech Republic, Project T400500402, and the Czech Ministry of Education, Youth and Sports, Projects MSM 4977751303 and MSM 6046137307.

\section{References}

1. Gutsche, C. D. Calixarenes Revisited. The Royal Society of Chemistry, Cambridge, 1998.

2. Böhmer, V. Angew. Chem., Int. Ed. Engl. 1995, 34, 713.

3. Arduini, A.; Pochini, A.; Reverberi, S.; Ungaro, R. Tetrahedron 1986, 42, 2089.

4. Arduini, A.; Ghidini, E.; Pochini, A.; Ungaro, R.; Andreetti, G.D.; Calestani, G.; Ugozzoli, F. J. Inclusion Phenom. 1988, 6, 119.

5. Arnaud-Neu, F.; Collins, E.M.; Deasy, M.; Ferguson, G.; Harris, S.J.; Kaitner, B.; Lough, A.J.; McKervey, M.A.; Marques, E.; Ruhl, B.L.; Schwing-Weill, M.J.; Seward, E.M. J. Am. Chem. Soc. 1989, 111, 8681.

6. Arnaud-Neu, F.; Barrett, G.; Harris, S.J.; Owens, M.; McKervey, M.A.; SchwingWeill, M.J.; Schwinté, P. Inorg. Chem. 1993, 32, 2644.

7. Ohto, K.; Murakami, E.; Shinohara, T.; Shiratsuchi, K.; Inoue, K.; Iwasaki, M. Anal. Chim. Acta 1997, 341, 275.

8. Ye, Z.; He, W.; Shi, X.; Zhu, L. J. Coord. Chem. 2001, 54, 105.

9. Danil de Namor, A.F.; Chahine, S.; Kowalska, D.; Castellano, E.E.; Piro, O.E. J. Am. Chem. Soc. 2002, 124, 12824.

10. Marcos, P. M.; Ascenso, J.R.; Segurado, M.A.P.; Pereira, J.L.C. J. Inclusion Phenom. 2002, 42, 281.

11. Marcos, P.M.; Félix, S.; Ascenso, J.R.; Segurado, M.A.P.; Pereira, J.L.C.; KhazaeliParsa, P.; Hubscher-Bruder, V.; Arnaud-Neu, F. New J.Chem. 2004, 28, 748.

12. Gutsche, C. D. Aldrichimica Acta 1995, $28,3$.

13. Křriž, J.; Dybal, J.; Makrlík, E.; Vaňura, P. Supramol. Chem. in print.

14. Křŕž, J.; Dybal, J.; Makrlík, E.; Vaňura, P. Supramol. Chem. in print.

15. Křŕž, J.; Dybal, J.; Makrlík, E.; Budka, J; Vaňura, P. Monatsh. Chem. in print.

16. Makrlík, E.; Vaňura, P. Talanta 1985, 32, 423.

17. Kř́̌ž, J.; Makrlík, E.; Vaňura, P. Biopolymers 2006, 81, 104.

18. Kř́žž, J.; Dybal, J.; Makrlík, E. Biopolymers 2006, 82, 536.

19. Meiboom, S.; Gill, D. Rev. Sci. Instrum. 1958, 29, 688.

20. Luz, L.; Meiboom, S. J. Chem. Phys. 1963, 39, 366. 
21. Canet, D.; Robert, J.B. in Dynamics of Solutions and Fluid Mixtures by NMR (J. J. Delpuech Ed.), Wiley, Chichester 1995, p. 127.

22. Frisch, M. J.; Trucks, G. W.; Schlegel, H. B.; Scuseria, G. E.; Robb, M. A.; Cheeseman, J. R.; Montgomery, Jr., J. A.; Vreven, T.; Kudin, K. N.; Burant, J. C.; Millam, J. M.; Iyengar, S. S.; Tomasi, J.; Barone, V.; Mennucci, B.; Cossi, M.; Scalmani, G.; Rega, N.; Petersson, G. A.; Nakatsuji, H.; Hada, M.; Ehara, M.; Toyota, K.; Fukuda, R.; Hasegawa, J.; Ishida, M.; Nakajima, T.; Honda, Y.; Kitao, O.; Nakai, H.; Klene, M.; Li, X.; Knox, J. E.; Hratchian, H. P.; Cross, J. B.; Bakken, V.; Adamo, C.; Jaramillo, J.; Gomperts, R.; Stratmann, R. E.; Yazyev, O.; Austin, A. J.; Cammi, R.; Pomelli, C.; Ochterski, J. W.; Ayala, P. Y.; Morokuma, K.; Voth, G. A.; Salvador, P.; Dannenberg, J. J.; Zakrzewski, V. G.; Dapprich, S.; Daniels, A. D.; Strain, M. C.; Farkas, O.; Malick, D. K.; Rabuck, A. D.; Raghavachari, K.; Foresman, J. B.; Ortiz, J. V.; Cui, Q.; Baboul, A. G.; Clifford, S.; Cioslowski, J.; Stefanov, B. B.; Liu, G.; Liashenko, A.; Piskorz, P.; Komaromi, I.; Martin, R. L.; Fox, D. J.; Keith, T.; AlLaham, M. A.; Peng, C. Y.; Nanayakkara, A.; Challacombe, M.; Gill, P. M. W.; Johnson, B.; Chen, W.; Wong, M. W.; Gonzalez, C.; and Pople, J. A. Gaussian 03, Revision C.02; Gaussian, Inc.: Wallingford CT, 2004.

23. Kelderman, E.; Derhaeg, L.; Heesink, G.J.T.; Verboom, W.; Engbersen, J.F.J.; van Hulst, N.F.; Persoons, A.; Reinhoudt, D.N. Angew. Chem. 1992, 104, 1107. 


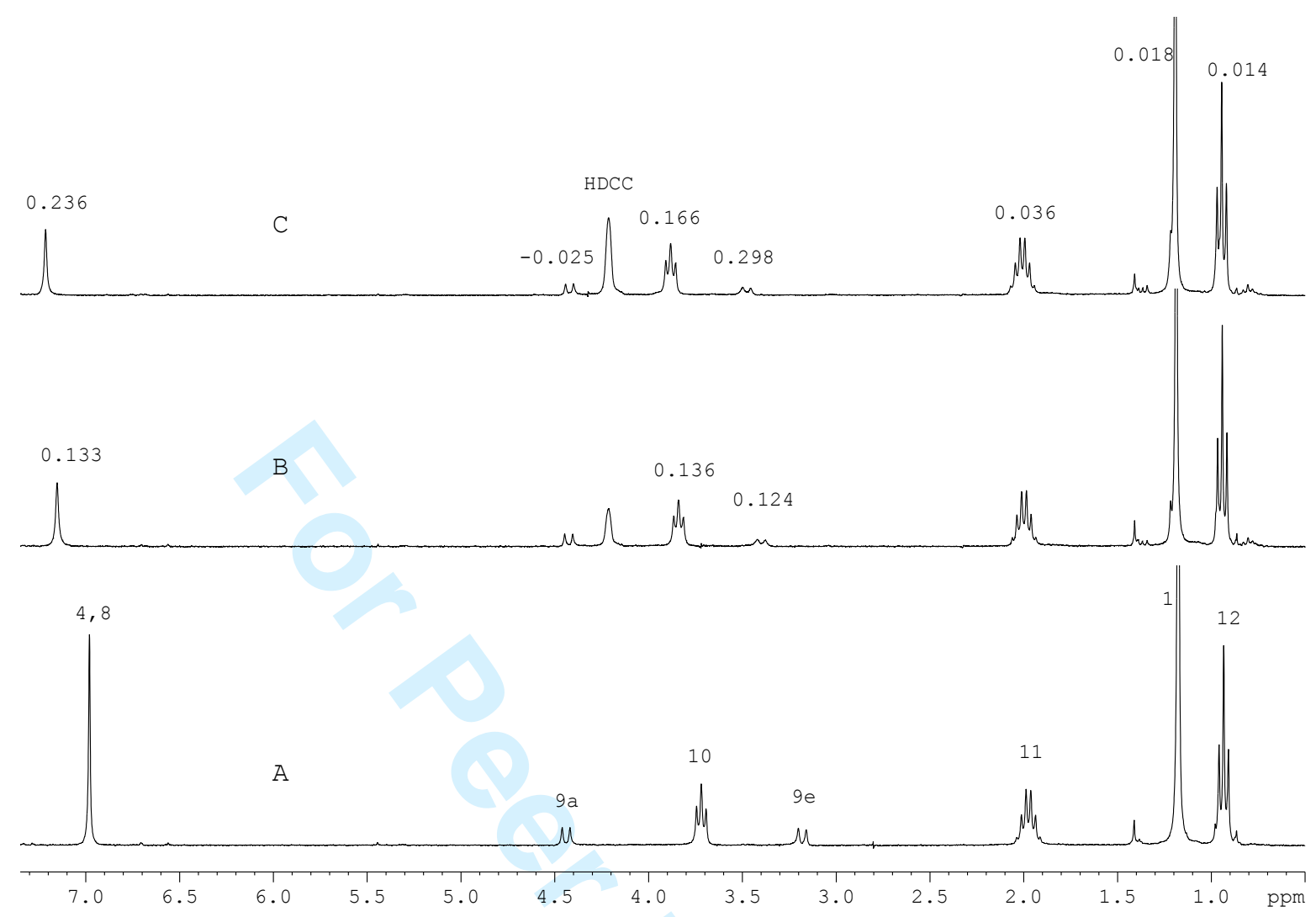




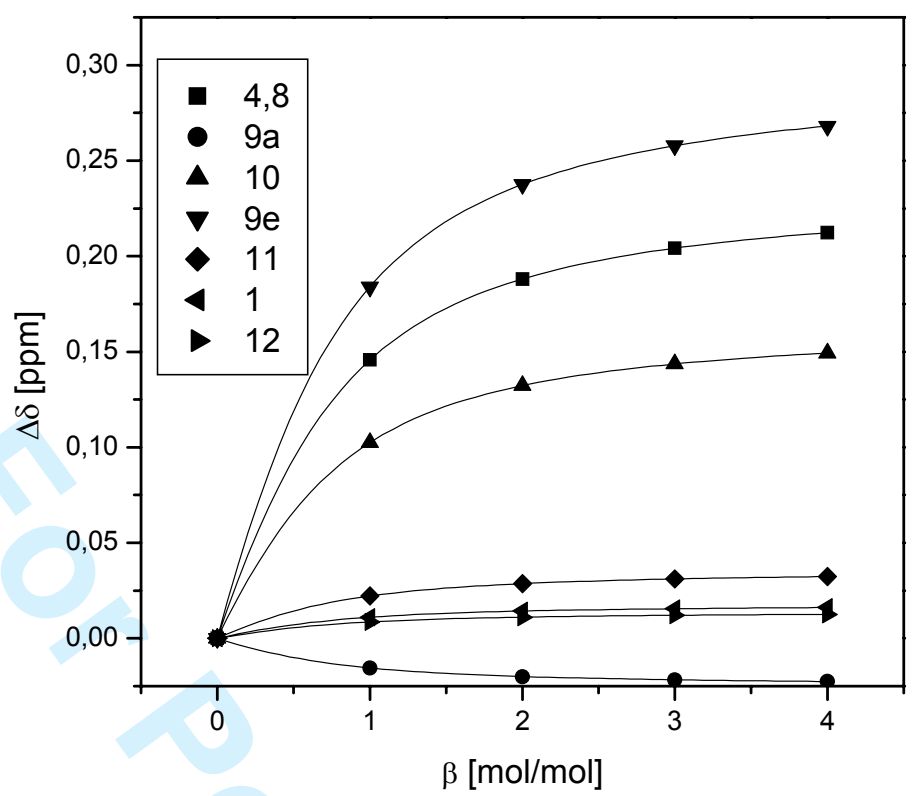




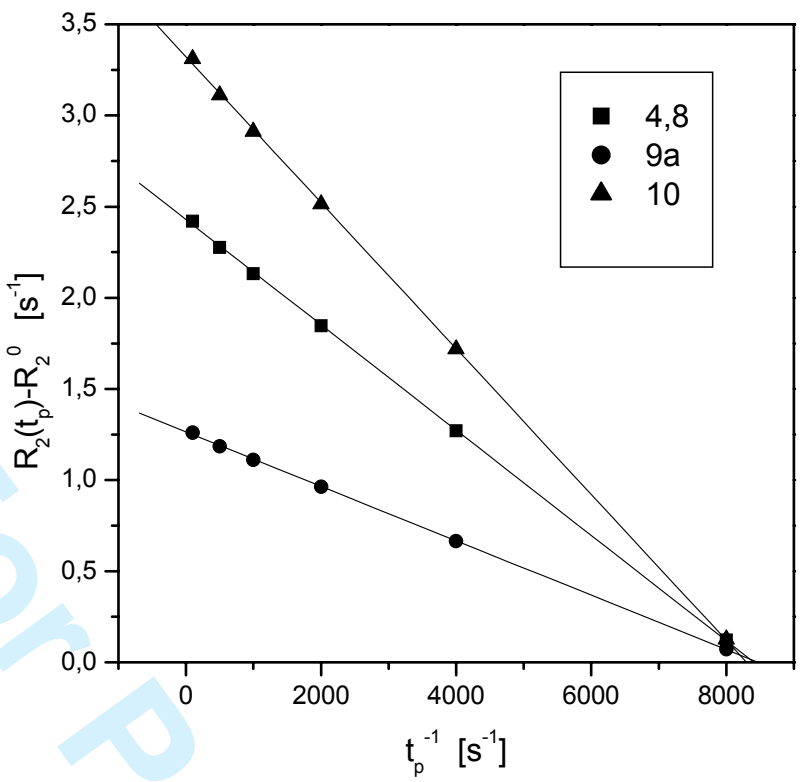




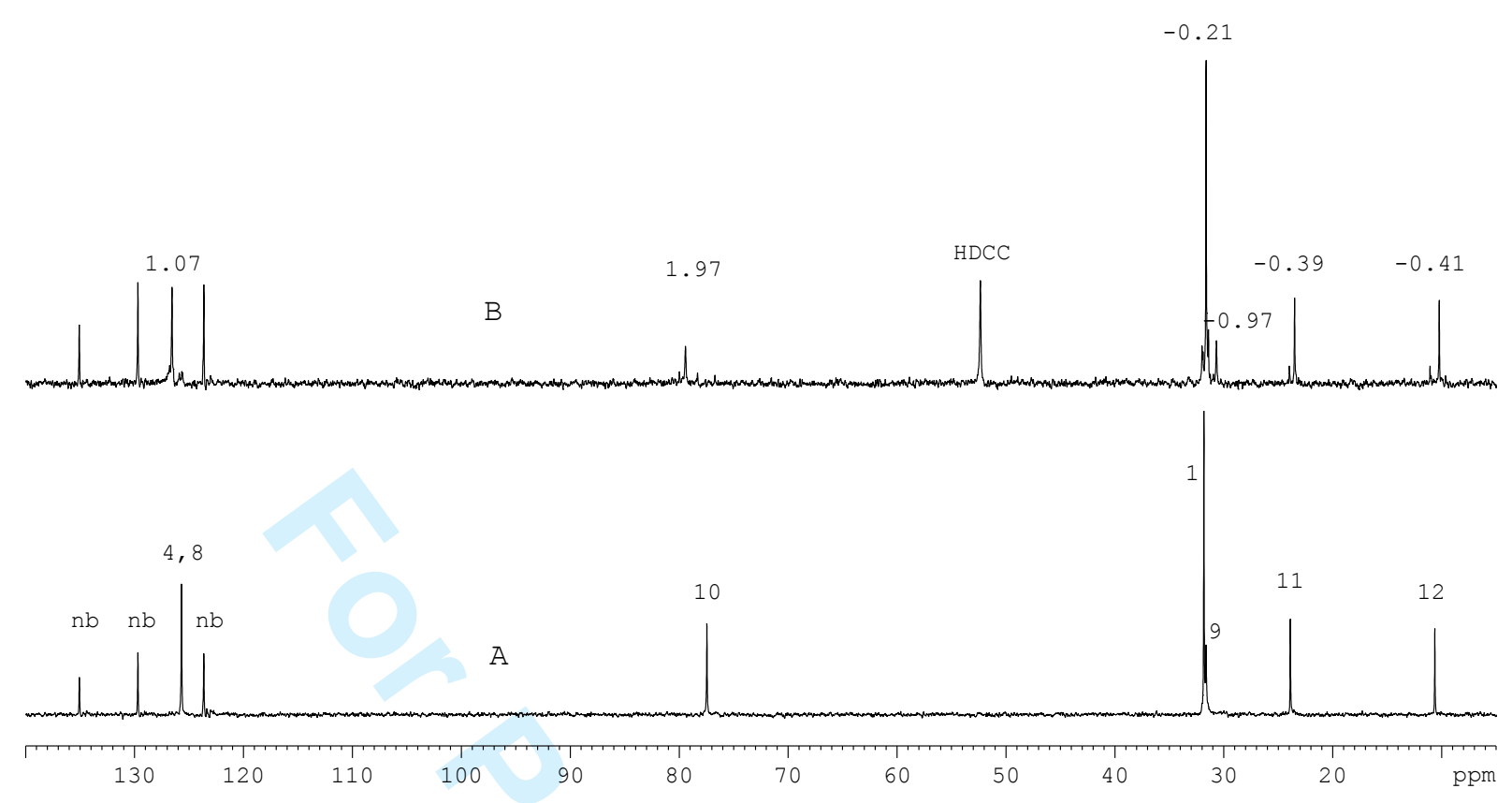



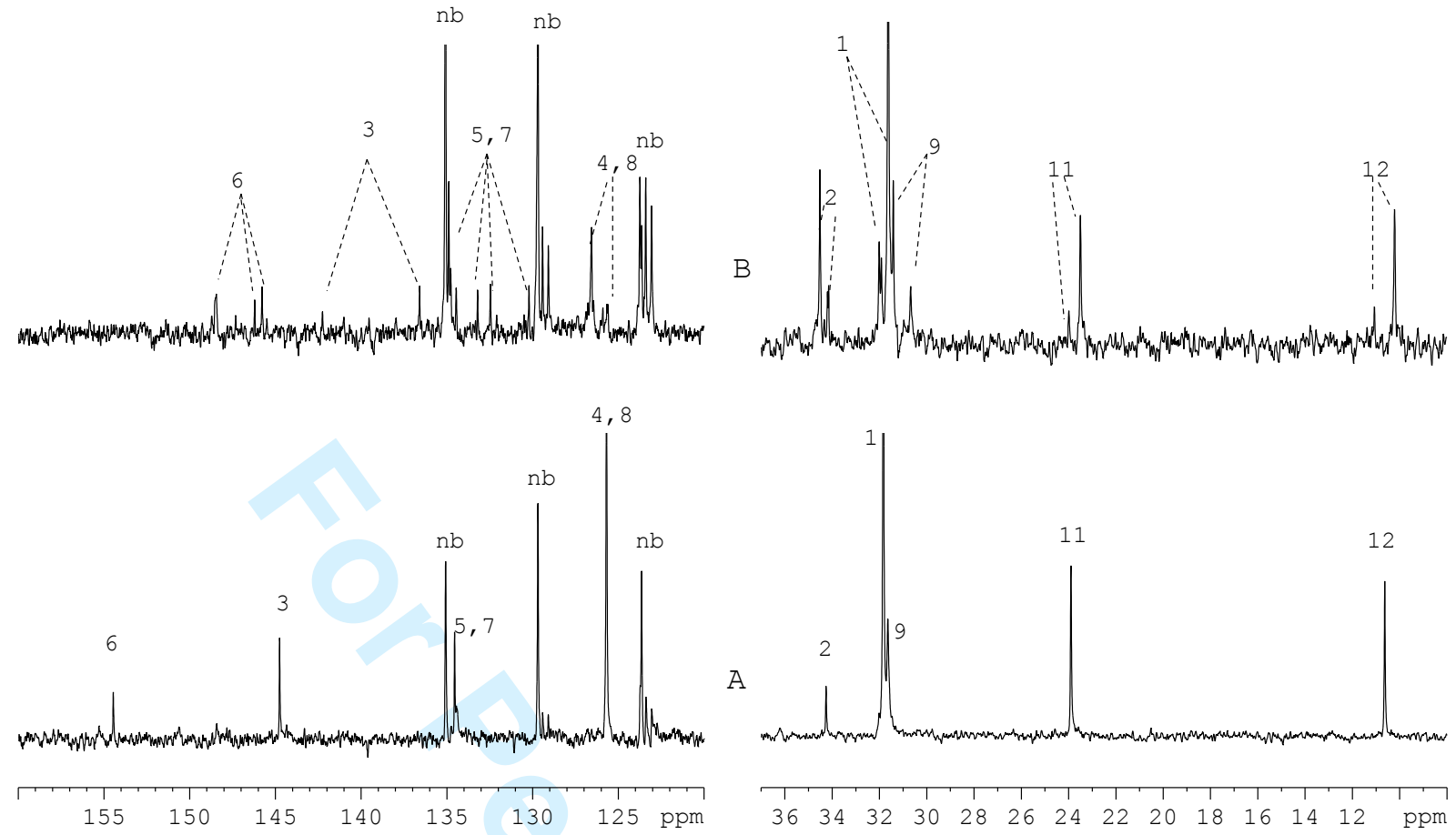

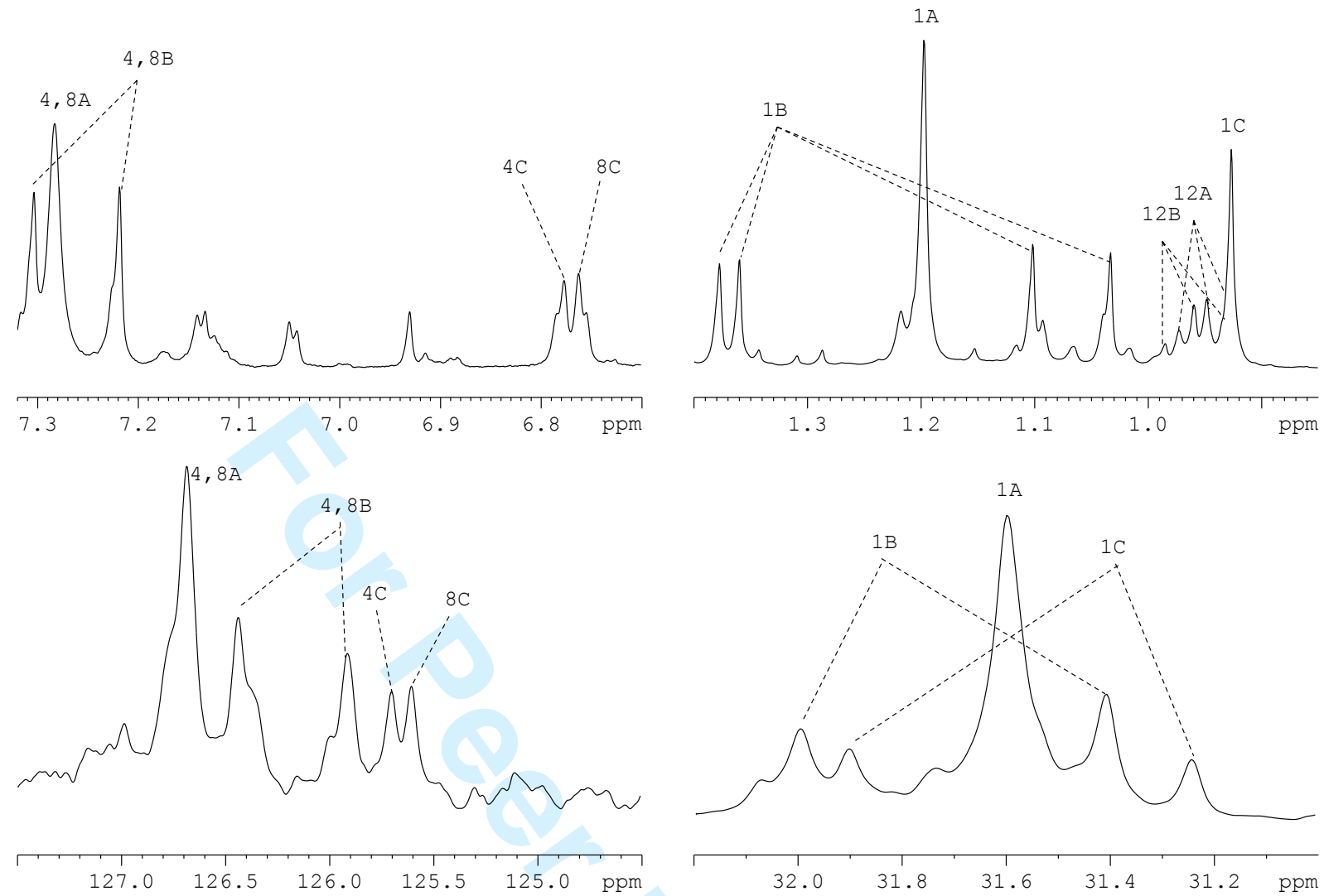

30

31

32

34

35

36

37

38

39

40

41

43

44

45

46

47

48

49

50

51 


1
2
3
4
5
6
7
8
9
10
11
12
13
14
15
16
17
18
19
20
21
22
23
24
25
26
27
28
29
30
31
32
33
34
35
36
37
38
39
40
41
42
43
44
45
46
47
48
49
50
51
52
53
54
55
56
57
58
59
60
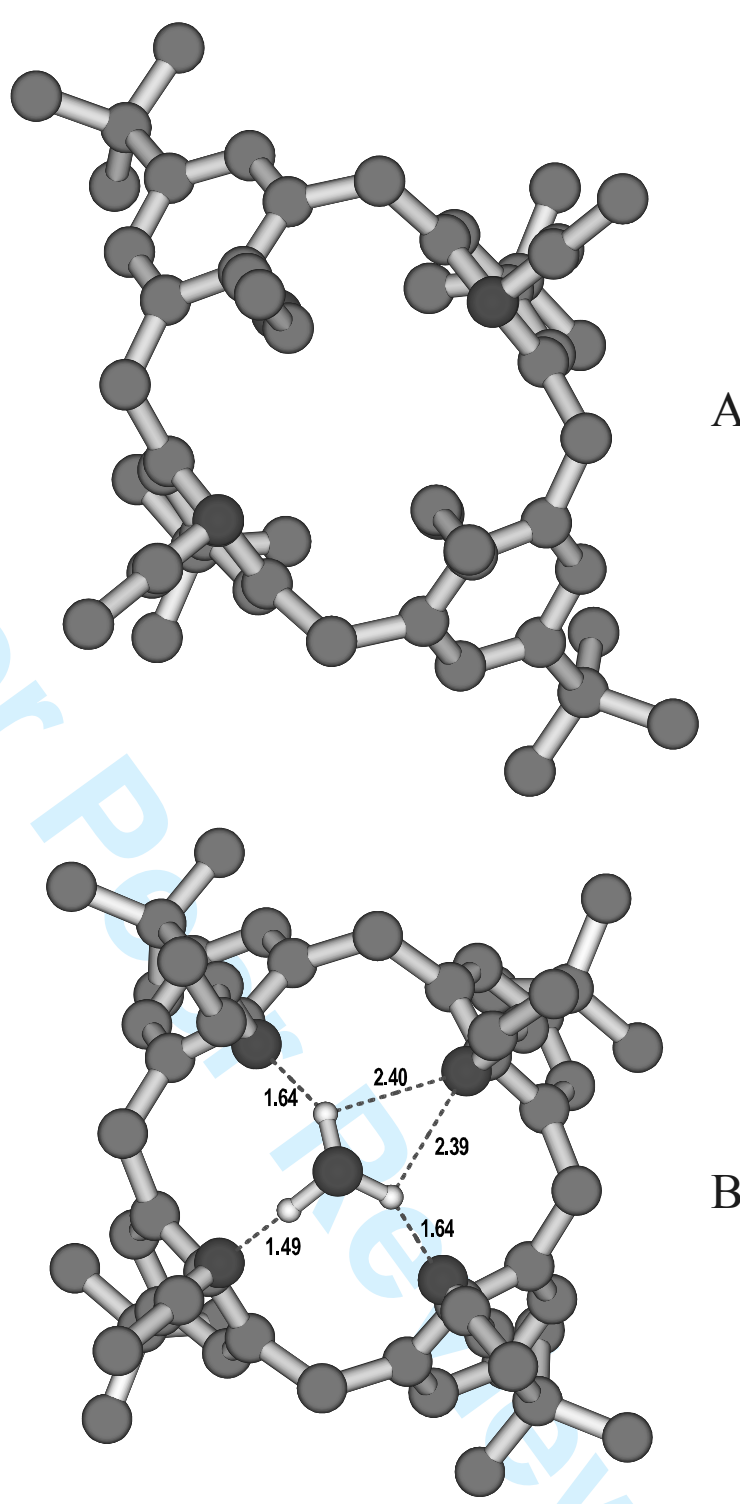


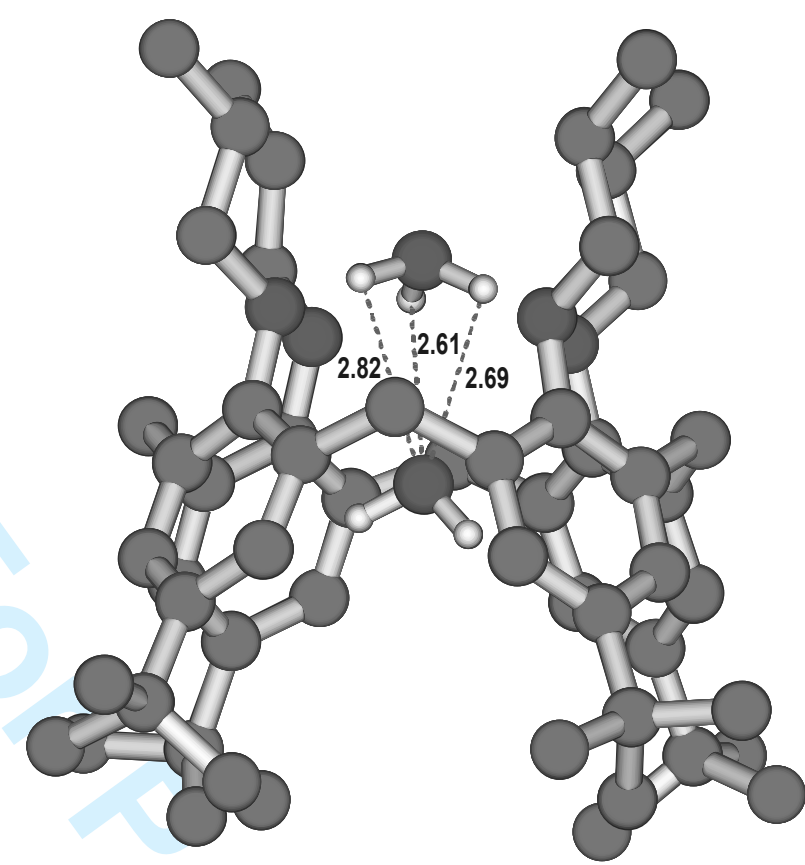

